\title{
From Mindy's Institute, Broadway
}

\author{
EUGENE MILNE
}

A first year medical student recently commented to me that in every lecture he attended he fell asleep after 45 minutes or so. Of course, with my years of experience of medical education I reassured him that with time and some effort he would be able to achieve this in as little as ten minutes or less.

Boredom in lectures is a fairly universal problem, and in a recent period of middle distance staring it occurred to me that the entertainment aspect of lectures might be improved if lecturers were to perform their spiel in character. Just to get them on the right track, here-with apologies to Damon Runyan - is a case from one of our colleagues across the Atlantic. If the history is somewhat clinically inaccurate this is a result of teaching appendicitis more than ten minutes into a lecture.

The patient in question is a patient name of Louis "Knuckles" Vincenti, so called on account of he has to lift his hands up to avoid damaging them on the pavement when walking. In fact Louis is by no means in line for a Nobel prize unless he picks one up in a poker game.

Anyhow, Louis comes up to me last week and says, "Doc, I am not feeling so good," and to tell the truth, although Louis does not look so good at the best of times, this day he is looking less good than usual, so I says to pull up a chair and tell me his problem. Well it seems that Louis is having a pain in his stomach that is bothering him more than somewhat, and let me tell you that Louis has more than ample stomach in which to be experiencing a pain.

At this I am concerned and inquire as to the nature of his stools, at which point Louis is about to flatten me for thinking I call him a pigeon until he realises that I refer to the other kind of stool which is associated with bowels rather than cops but which is not entirely dissimilar in character. "Doc," says Louis, "they are not exactly flowing freely, but then again they are not standing to attention either, and are otherwise in a similar state to any other time which is not a state I am in the habit of paying much attention to. But I notice," he continues, "that I am feeling like something I eat does not like me and wishes to be rehabilitated. And also Wilhelmina tells me my hally toes is worse than usual though I don't see they look any different."

The Wilhelmina to whom Louis refers, incidentally, is a Judy with whom I am familiar - though not, I am told, nearly so familiar as a large number of guvs in the New Jersey area-and who is Louis's ever loving Mrs Knuckles.

So I decide to pursue a little of Louis's medical history, which is of little interest except where his mother was doing the worrying. The trauma department, however, is full to bursting and Louis is on the point of forgetting his pain and describing all of his injuries when he lets out a groan and clasps his abdomen again. I take this opportunity to continue my questions as the stories of Louis's injuries are by no means new to me and in fact I can recite them in my sleep.

Louis continues to tell me between groans that he is an only child, which to my way of thinking is a blessing to humanity, and his mother has never a day's illness in her life and is living with a miner in Nevada. His father, on the other hand, is last seen on the back end of a train headed for California shortly after the stork delivers little Lou, which, to a great many people, indicates that Mr Vincenti senior is a man of very great taste and sensibility.

As I am already aware, Louis has a considerable taste for the

\section{Newcastle upon Tyne}

EUGENE MILNE, medical student

Correspondence to: 41 Deuchar Street, Jesmond, Newcastle upon Tyne. bottle and drinks like a fish. A big fish. Very possibly a whale. He also is fond of tobacco, and cannot remember how many he smokes though it may be between five and 70 a day. In response to my inquiry as to whether he is on any drugs at the moment I am told that he never touches them except by way of business, which is not an aspect of business of which he is particularly fond. He also tells me that he is allergic to cops and horse dopers in that order, though the salvation army brings him out in a nasty rash as well.

Well I continue to ask Louis about the function of various parts of his anatomy, all of which are working, only I omit to ask about his nervous system because he begins to look bored, and in any case most of what makes him tick is spinal, except for perhaps the bit that works out the odds on horses. I proceed to examine the patient and find something of a fever and some tenderness around where he slips his Mama's leash, so I decide to admit him to hospital for a little observation.

Pretty soon $\mathrm{Mr}$ Vincenti is moaning and groaning and retching like it was Saturday night and the horses came in - which is no way for a respected citizen such as Louis to be behaving in a public place-and the pain has gone walkies around his large Italian tummy. At this the poor guy is really getting worried that the pain will go wandering round places where he would rather it did not go, but this is prevented as I take him to the operating room and remove a small but considerably angry piece of him.

The next morning after I remove Louis's appendix I arrive on the ward to find him running the nurses around like bees round a honey pot. So I personally address Lou and tell him that if he does not cease his hollerin' I am operating and replacing the offending item very shortly.

By two days after operation the patient is making his recovery at high speed, only slightly impaired by receiving a black eye at the end of Nurse Brannigan's left hook, and let me tell you that Nurse Brannigan delivers a considerable left hook as I receive it once myself in a laundry closet. Nevertheless, Louis is telling Nurse Brannigan that she is very very wonderful, when I would tell Louis that when Nurse Brannigan opens her mouth a light goes on.

After three days Louis is looking about as good as he ever does and perhaps a little better because he has kinda cute jamees, but the staff are growing somewhat fatigued with him, especially as he keeps trying to get odds on the operations, so I decide to discharge him into the hands of his ever loving Wilhelmina.

Which about wraps it up I guess, except for a brief follow up consultation, which I am having with Louis between the 230 and 3 0 -clock races last Saturday. And of course my reputation is greatly improved as the only guy ever to put a knife into Louis Vincenti without very soon finding both his legs broke.

Best regards,

Harry "the Doc" Bronowski.

Is it too late to complain about the misuse of the word "doctor"?

SIR,-Nowadays, every member of my profession, even the lowest qualified such as a member of the Society of Apothecaries (LMSSA) is addressed as "doctor." One does not call one's curate doctor if he is a bachelor of divinity, nor his organist thus if he is only a bachelor of music.

When I sent my thesis for a doctorate to the registrar at Cambridge I accompanied it with a letter on my practice notepaper. He pointed to the heading, Doctor X, saying drily, "A trifle premature, I think, Mister X." After the ceremony, when he gave me my certificate, he smiled and said, "You may keep that notepaper, Doctor." What is the alternative? "Healer" smacks of faith healing. What about "treater"? After all doctors treat, only God can heal. To save myself from being lynched by some of my colleagues I simply sign myself-Anonymous, $\mathrm{MD}$.

Published by the Proprietor, THE BRITISH MEDICAL ASSOCIATION, Tavistock Square, London WC1H 9JR, and printed in Great Britain by George Pulman and Sons Limited of London and Bletchley. Typesetting by Bedford Typesetters Limited, Bedford. 